\title{
Multi-Searcher Optimization for the Optimal Energy Dispatch of Combined Heat and Power-Thermal-Wind-Photovoltaic Systems
}

\author{
Jianlin Tang ${ }^{1} \mathbb{D}$, Tao $\mathrm{Yu}^{1, * \mathbb{C}}$, Xiaoshun Zhang ${ }^{2, *}$, Zhuohuan $\mathrm{Li}^{1}$ and Junbin Chen ${ }^{1}$ \\ 1 College of Electric Power, South China University of Technology, Guangzhou 510640, China; \\ tang-j1@foxmail.com (J.T.); lizhuohuan001@foxmail.com (Z.L.); junbin0617@outlook.com (J.C.) \\ 2 College of Engineering, Shantou University, Shantou 515000, China \\ * Correspondence: taoyu1@scut.edu.cn (T.Y.); xiaoshunzhang@stu.edu.cn (X.Z.); Tel.: +86-130-0208-8518 (T.Y.); \\ +86-150-1752-7246 (X.Z.)
}

Received: 2 January 2019; Accepted: 30 January 2019; Published: 5 February 2019

\begin{abstract}
This paper proposes a novel multi-searcher optimization (MSO) algorithm for the optimal energy dispatch (OED) of combined heat and power-thermal-wind-photovoltaic systems. The available power of wind turbine (WT) units and photovoltaic (PV) units is approximated with the probability density functions of wind speed and solar irradiance, respectively. The chaos theory is used to implement a wide global search, which can effectively avoid a low-quality local optimum for OED. Besides, a double-layer searcher is designed to guarantee fast convergence to a high-quality optimal solution. Finally, three benchmark functions and an energy system with 27 units are used for testing the performance of the MSO compared with nine other frequently used heuristic algorithms. The simulation results demonstrate that the proposed technique not only can solve the highly nonlinear, non-smooth, and non-convex OED problem of an energy system, but can also achieve a superior performance for the convergence speed and the optimum quality.
\end{abstract}

Keywords: multi-searcher optimization; chaos theory; double-layer searcher; optimal energy dispatch; complex energy system

\section{Introduction}

As one of the critical operation tasks of power systems, economic dispatch (ED) is usually employed to minimize the total operating cost via optimally calculating the active power outputs of all the generators to balance the active power demand under various operating constraints [1]. However, the conventional ED only considers the electricity energy dispatch of the thermal units, which cannot satisfy the operation requirement of an integrated energy system (IES) with various energy types and sources.

In light of this issue, the ED problem of an IES has attracted extensive investigation. By incorporating customer aggregators' flexible energy demand into the centralized energy dispatch model, a two-level optimization problem [2] was formed in the heat and power IES. In [3], a regional integrated energy system including wind turbines (WT), photovoltaics (PV), gas turbines and battery energy storage was introduced to minimize the operating costs of the system and determine the optimal coordination between the various energy sources. In order to fully exploit the economic and environmental advantages of the system, considering the difficulties of information collection from subareas, a novel decentralized optimal multi-energy flow (OMEF) for large-scale IESs in a carbon trading market was proposed in [4]. The improved differential evolution algorithm [5] was designed to obtain the minimum operation cost of the IES, while considering battery lifetime loss. 
In [6], a novel multi-agent bargaining learning (MABL) model was employed for the distributed energy hub economic dispatch (EHED) of multiple energy carrier systems (MECS). Among these studies, the combined heat and power ED is the most frequent research interest. Similarly, it usually aims to minimize the total operating cost while satisfying the electricity and heat energy balance constraints and other operating constraints. In order to take the wind and PV energy into account, their stochastic and intermittent power outputs were introduced in the combined heat and power ED via construction of the probability density functions of the wind speed and solar irradiance [7]. Particularly, this new ED is also called the optimal energy dispatch (OED) of the combined heat and power-thermal-wind-photovoltaic systems in this paper. In essence, it is a highly complex optimization with highly non-smooth, non-linear, and non-convex features, due to the uncertainty of wind and PV energy outputs, the valve-point loading effect of thermal generators, and the non-convex feasible operating region constraint of combined heat and power (CHP) units.

Generally speaking, the presented OED can be addressed by two types of methods. The first type is a classical optimization algorithm, e.g., the quadratic programming method [8], interior point method [9], and the Newton method [10]. However, most of them are gradient-based optimization methods, which are highly dependent on a specific mathematical model. If the optimization is non-linear with discontinuous functions and multiple local optimums, this will easily trap into a low-quality local optimum, especially for the OED. On the other hand, it can be also solved by metaheuristic optimization algorithms, such as genetic algorithms (GA) [11], particle swarm optimization (PSO) [12], differential evolution (DE) algorithms [13] and the grey wolf optimizer (GWO) [14], which are highly independent from the specific mathematical models, and are much easier to apply for OED compared to the first type of method. Motivated by this advantage, this paper proposes a novel algorithm named multi-searcher optimization (MSO) for the OED of combined heat and power-thermal-wind- photovoltaic systems, which has the following novelties:

- Traditional ED only considers the electricity energy dispatch of power systems, but does not consider the heat energy dispatch of thermal systems. In contrast, the presented OED can achieve electricity and heat energy dispatch simultaneously, while the stochastic characteristics of wind and PV energy are fully taken into account;

- Through combination with the chaos theory, the global search ability of the MSO can be effectively enhanced. Besides, a double-layer searcher is designed to accelerate the convergence of MSO, while a high-quality optimal solution can be guaranteed. Compared with nine existing heuristic algorithms, the proposed MSO can search a higher quality dispatch scheme for OED within a shorter computation time.

The rest of the paper is structured as follows: Section 2 details the mathematical model of OED of combined heat and power-thermal-wind-photovoltaic systems. Section 3 gives the detailed operations of the MSO and its application for OED. A discussion and analyses of case studies is given in Section 4 . Section 5 concludes the main contributions of this study.

\section{Mathematical Model of OED of Combined Heat and Power-Thermal-Wind-Photovoltaic Systems}

The OED framework of combined heat and power-thermal-wind-photovoltaic systems is illustrated in Figure 1. The supply side consists of thermal units, combined heat and power (CHP) plants, heating plants, WT units and PV units. The generated electricity and heat energy are transmitted to the demand side through lines and pipelines. This study aims to minimize the total operating cost of the whole system while satisfying all the constraints, including energy balance constraints, the capacity limits of all energy sources and feasible operating region constraints of $\mathrm{CHP}$ units. 


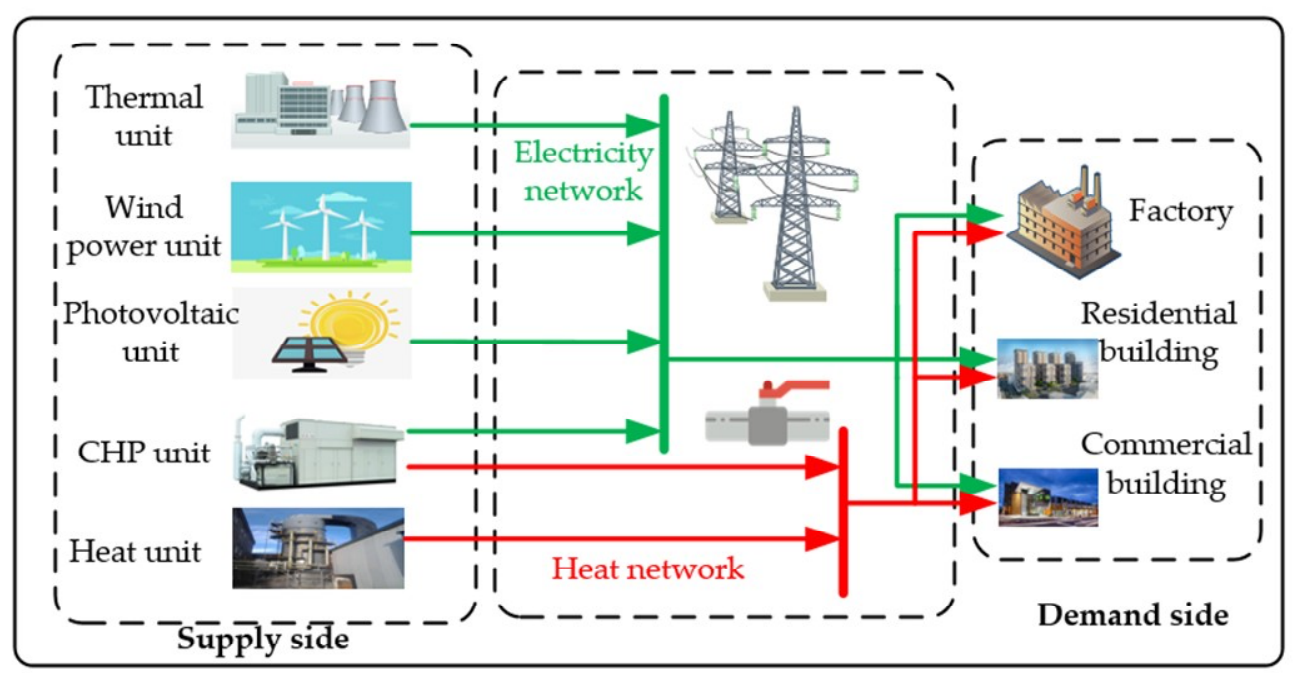

Figure 1. Optimal energy dispatch (OED) framework of combined heat and power-thermalwind-photovoltaic systems.

\subsection{Renewable Energy}

\subsubsection{Relationship between Wind Speed and Wind Power Output}

The power output of a WT unit is mainly determined by the probability distribution parameter of wind speed. In general, the wind speed probability distribution can be described by different models, including Weibull distribution, Rayleigh distribution, log-normal distribution, and normal distribution. Since the two-parameter Weibull model can adjust the parameters to adapt to the periodic variation of wind speed, it is the most frequently used model for wind speed probability distribution, in which the cumulative distribution function can be written as follows $[15,16]$ :

$$
\begin{gathered}
f_{V}(v)=\frac{k}{c}\left(\frac{v}{c}\right)^{(k-1)} \exp \left[-\left(\frac{v}{c}\right)^{k}\right] \\
F_{V}(v)=\int_{0}^{v} f_{V}(\xi) d \xi=1-\exp \left[-\left(\frac{v}{c}\right)^{k}\right]
\end{gathered}
$$

where $V$ represents the speed random variable, $v$ is the wind speed, $k$ is the shape factor of the wind speed probability distribution function, which determines the overall shape of the wind speed probability distribution density curve, and $c$ is the scale factor of the wind speed probability distribution function, which reflects the average wind speed of the wind field and can enlarge or reduce the curve, but does not affect the shape of the distribution density curve.

Assuming that the output characteristic of a WT is a simplified piecewise linear function, its power output can be calculated according to the given wind speed [17]:

$$
p_{w t}= \begin{cases}0 & v<v_{\text {in }}, v>v_{\text {out }} \\ p_{w t}^{r} \frac{v-v_{\text {in }}}{v_{r}-v_{\text {in }}} & v_{\text {in }} \leq v \leq v_{r} \\ p_{w t}^{r} & v_{r}<v \leq v_{\text {out }}\end{cases}
$$

where $p_{w t}$ is the current maximum power points of the WT unit, $p_{w t}^{r}$ is the rated power of the WT unit, $v_{r}$ is the rated wind speed, $v$ is the current wind speed, and $v_{i n}$ and $v_{\text {out }}$ are the cut-in and cut-out wind speeds, respectively.

The probability distribution of wind speed is converted into the probability distribution of wind power by a linear transformation [18]:

$$
P_{\mathrm{WT}}=T(V)=e V+f
$$




$$
f_{P_{W T}}\left(p_{w t}\right)=f_{V}\left[T^{-1}\left(p_{w t}\right)\right]\left[\frac{d T^{-1}\left(p_{w t}\right)}{d p_{w t}}\right]=f_{V}\left(\frac{p_{w t}-f}{e}\right)\left|\frac{1}{e}\right|
$$

where $V$ and $P_{W T}$ are the wind speed random variable and the wind power random variable, respectively, and $T$ represents a transformation.

For the Weibull function, the discrete part of the wind power output can be written as follows:

$$
\begin{aligned}
& F_{P_{W T}\left(p_{w t}=0\right)=} F_{V}\left(v_{\text {in }}\right)+\left(1-F_{V}\left(v_{\text {out }}\right)\right) \\
& =1-\exp \left(-\left(\frac{v_{\text {in }}}{c}\right)^{k}\right)+\exp \left(-\left(\frac{v_{\text {out }}}{c}\right)^{k}\right) \\
& F_{P_{W T}\left(p_{w t}=p_{w t}^{r}\right) \quad}=F_{V}\left(v_{\text {out }}\right)-F_{V}\left(v_{r}\right) \\
& =\exp \left(-\left(\frac{v_{r}}{c}\right)^{k}\right)-\exp \left(-\left(\frac{v_{\text {out }}}{c}\right)^{k}\right)
\end{aligned}
$$

If the output power of the fan is in a continuously changing range, the probability density function of the Weibull model can be described as follows:

$$
\begin{gathered}
f_{P_{W T}}\left(p_{w t}\right)=\left(\frac{k \varphi v_{i n}}{c p_{w t}^{r}}\right)\left[\frac{\left(1+\varphi p_{w t} / p_{w t}^{r}\right) v_{i n}}{c}\right] \exp \left\{-\left[\frac{\left(1+\varphi p_{w t} / p_{w t}^{r}\right) v_{i n}}{c}\right]^{k}\right\} \\
\varphi=\frac{v_{r}-v_{i n}}{v_{i n}}
\end{gathered}
$$

\subsubsection{Relationship between Solar Irradiance and Solar Power Output}

According to the statistics, solar irradiance is subject to Beta distribution over a certain period of time [19], whose probability density function can be written as follows:

$$
\begin{gathered}
f_{R}(r)=\frac{\Gamma(\partial+l)}{\Gamma(\partial) \Gamma(l)}\left(\frac{r}{r_{\max }}\right)^{\partial-1}\left(1-\frac{r}{r_{\max }}\right)^{l-1} \\
\partial=\mu\left[\frac{\mu(1-\mu)}{\sigma^{2}-1}\right] \\
l=(1-\mu)\left[\frac{\mu(1-\mu)}{\sigma^{2}-1}\right]
\end{gathered}
$$

where $r_{\max }$ is maximum solar irradiance, $r$ is the solar irradiance, $\mu$ is the mean, and $\sigma$ is the standard deviation.

Generally speaking, the output power of a PV cell is linearly matched with the solar irradiance. If power loss is not considered, and the influence of the ambient temperature is ignored, the output power of a PV unit can be described by $[20,21]$ :

$$
p_{p v}=r A \eta
$$

where $A$ is the total area of the PV cell and $\eta$ is the PV cell efficiency.

Therefore, the probability density function of the PV cell can be derived as follows:

$$
f_{P_{P V}}\left(p_{p v}\right)=\frac{1}{A \eta} \frac{\Gamma(\partial+l)}{\Gamma(\partial) \Gamma(l)}\left(\frac{p_{p v}}{p_{p v}^{\max }}\right)^{\partial-1}\left(1-\frac{p_{p v}}{p_{p v}^{\max }}\right)^{l-1}
$$

where $p_{p v}$ is the output power of a PV cell and $p_{p v}^{\max }$ is the maximum generated power. 


\subsection{Objective Function}

In this study, the objective function of OED is the minimization of the total operating cost, which can be calculated as follows:

$$
\begin{gathered}
C_{\text {total }}=C_{i}\left(P_{i}^{p}\right)+C_{j}\left[P_{j}^{c}, H_{j}^{c}\right]+C_{k}\left(H_{k}^{h}\right)+C_{w t, l}\left(P_{l}\right)+C_{p v, m}\left(P_{m}\right) i=1,2, \ldots, N_{P} ; j=1,2, \ldots, N_{c} \\
k=1,2, \ldots, N_{k} ; l=1,2, \ldots, N_{l} ; m=1,2, \ldots, N_{m}
\end{gathered}
$$

where $C_{i}\left(P_{i}^{p}\right)$ with $i=1,2, \ldots, N_{p}$ represents the cost function of the $i$ th thermal unit, $C_{j}\left[P_{j}^{c}, H_{j}^{c}\right]$ with $j=1,2, \ldots, N_{c}$ represents the cost function of the $j$ th $C H P, C_{k}\left(H_{k}^{h}\right)$ with $k=1,2, \ldots, N_{k}$ represents the cost function of the $k$ th heat-only unit, $C_{w t, l}\left(P_{l}\right)$ with $l=1,2, \ldots, N_{l}$ represents the cost function of the $l$ th WT unit, $C_{p v, m}\left(P_{m}\right)$ with $m=1,2, \ldots, N_{m}$ represents the cost function of the $m$ th PV unit, and $N_{p}$, $N_{c}, N_{k}, N_{l}$ and $N_{m}$ are the number of conventional units, CHP units, heat-only units, WT units and PV units, respectively.

\subsubsection{Thermal Units}

In general, the fuel cost of a thermal unit can be expressed by a quadratic function. However, a thermal unit usually has multiple valves for controlling the power output. When the steam admission valves in thermal units are first opened, a sudden increase in losses is observed. This leads to ripples in the cost function, which is known as valve-point loading. Hence, the fuel cost function needs to increase a rectified sinusoidal component by considering this effect. The operating cost of the thermal units can be written as follows [22]:

$$
C_{i}\left(P_{i}^{p}\right)=a_{i}\left(P_{i}^{p}\right)^{2}+b_{i} P_{i}^{p}+c_{i}+\left|d_{i} \sin \left(e_{i}\left(P_{i}^{P_{\min }}-P_{i}^{p}\right)\right)\right| i=1,2, \ldots, N_{P}
$$

where $a_{i}, b_{i}, c_{i}, d_{i}$, and $f_{i}$ are cost coefficients of the $i$ th thermal unit, $p_{i}^{p \min }$ represents the minimum power generation limit of the $i$ th thermal unit, and $P_{i}^{p}$ is the electricity energy output of the $i$ th thermal unit.

\subsubsection{CHP Units}

The CHP cost function is usually expressed as a quadratic polynomial function of the heat and electricity power output of a CHP unit, which appends a coupling coefficient that relates electricity power and heat. Hence, the operating cost of a CHP unit is determined simultaneously by its heat and electricity energy outputs, as follows [23]:

$$
C_{j}\left[P_{j}^{c}, H_{j}^{c}\right]=a_{j}\left(P_{j}^{c}\right)^{2}+b_{j} P_{j}^{c}+c_{j}+d_{j}\left(H_{j}^{c}\right)^{2}+e_{j} H_{j}^{c}+f_{j} H_{j}^{c} P_{j}^{c} j=1,2, \ldots, N_{c}
$$

where $a_{j}, b_{j}, c_{j}, d_{j}, e_{j}$ and $f_{j}$ are the operating cost coefficients of the $j$ th $\mathrm{CHP}$ unit, $P_{j}^{c}$ is the electricity energy output of the $j$ th $\mathrm{CHP}$ unit, and $H_{j}^{c}$ is the heat energy output of the $j$ th CHP unit.

\subsubsection{Heat-Only Units}

Compared with the CHP unit, the heat-only unit can only generate the heat energy. From the result of experiments for the generation of characteristic of heat only units, the operating cost can be described as a quadratic function [24]:

$$
C_{k}\left(H_{k}^{h}\right)=a_{k}\left(H_{k}^{h}\right)^{2}+b_{k} H_{k}^{h}+c_{k} k=1,2, \ldots, N_{k}
$$

where $a_{k}, b_{k}$ and $c_{k}$ are the operating cost coefficients of the $k$ th heat-only unit, and $H_{k}^{h}$ is the heat energy output of the $k$ th heat-only unit. 


\subsubsection{WT Units}

In general, WT units are privately owned and grid operators need to purchase electricity energy from them with a power purchase agreement and a certain payment. The payment consists of three parts, in which the first part is the direct cost of buying wind power. A linear cost function can be assumed for the direct cost of WT, as follows [25]:

$$
C_{d, w t, l}\left(P_{l}\right)=d_{w w, l} P_{w t, l} l=1,2, \ldots, N_{l}
$$

where $d_{w w t, l}$ is the direct cost coefficients of the $l$ th wind power and $P_{w t, l}$ is the electricity energy output of the $l$ th wind power.

The second part is the penalty cost for underestimation of wind power output due to its high randomness. When the planned wind power is lower than the available wind power, the excess wind energy is wasted and needs to be translated into the penalty cost. The penalty cost for not using all the available wind power will be linearly related to the difference between the available wind power and the planned wind power, as follows [25]:

$$
C_{u e, w t, l}\left(P_{l}\right)=K_{u e, w t, l} \int_{P_{w t, l}}^{P_{w t, r a t e, l}}\left(p_{w t}-P_{w t, l}\right) f_{P_{W T}}\left(p_{w t}\right) d p_{w t} l=1,2, \ldots, N_{l}
$$

where $K_{u e, w t, l}$ is the underestimated coefficient of the $l$ th wind power, $P_{w t, r a t e, l}$ is the rated power generation of the $l$ th wind power, and $P_{w t, l}$ is the scheduled power generation of the $l$ th wind power.

The third part is the ancillary cost generated by overestimated wind power output. If the scheduled wind power output is higher than the actual available wind power, then the backup power source should be obtained elsewhere to meet the load demand. Similar to the second part, the ancillary cost is also linearly related to the difference between the available wind power and the scheduled wind power, multiplied by the wind power output probability function. Hence, the ancillary cost can be calculated as:

$$
C_{o e, w t, l}\left(P_{l}\right)=K_{o e, w t, l} \int_{0}^{P_{w w t, l}}\left(P_{w w, l}-p_{w t}\right) f_{P_{W T}}\left(p_{w t}\right) d p_{w t} l=1,2, \ldots, N_{l}
$$

where $K_{o e, w t, l}$ is the overestimated coefficient of the $l$ th wind power.

According to the Equations (19)-(21), the total operating cost of a wind plant can be calculated as follows:

$$
C_{w t, l}\left(P_{l}\right)=C_{d, w t, l}\left(P_{l}\right)+C_{o e, w t, l}\left(P_{l}\right)+C_{u e, w t, l}\left(P_{l}\right) l=1,2, \ldots, N_{l}
$$

\subsubsection{PV Units}

To avoid unnecessary complexity, we assumed the cost function of PV units was similar to WT units. This addition was composed of three parts and calculated as a proposed approach [25]:

$$
\begin{gathered}
C_{p v, m}\left(P_{m}\right)=C_{d, p v, m}\left(P_{m}\right)+C_{o e, p v, m}\left(P_{m}\right)+C_{u e, p v, m}\left(P_{m}\right) m=1,2, \ldots, N_{m} \\
C_{d, p v, m}\left(P_{m}\right)=d_{p v, m} P_{p v, m} m=1,2, \ldots, N_{m} \\
C_{u e, p v, m}\left(P_{m}\right)=K_{u e, p v, m} \int_{P_{p v, m}}^{P_{p v, r a t e, m}}\left(p_{p v}-P_{p v, m}\right) f_{P_{P V}}\left(p_{w t}\right) d p_{w t} m=1,2, \ldots, N_{m} \\
C_{o e, p v, m}\left(P_{m}\right)=K_{o e, p v, m} \int_{0}^{P_{p v, m}}\left(P_{p v, m}-p_{p v}\right) f_{P_{P V}}\left(p_{w t}\right) d p_{w t} m=1,2, \ldots, N_{m}
\end{gathered}
$$

where $d_{p v, m}$ is the direct cost coefficients of the $m$ th PV power unit, $K_{u e, p v, m}$ is the underestimated coefficient of the $m$ th PV unit, and $K_{o e, p v, m}$ is the overestimated coefficient of the $m$ th PV unit. 


\subsection{Constraints}

\subsubsection{Equality Constraints}

The energy balance constraints are the most essential requirements for OED, i.e., the electricity and heat energy outputs from the energy suppliers need to be equal to the energy demands, which can be written as follows:

$$
\begin{gathered}
\sum_{i=1}^{N_{P}} P_{i}^{p}+\sum_{j=1}^{N_{c}} P_{j}^{c}+\sum_{l=1}^{N_{l}} P_{l}+\sum_{m=1}^{N_{m}} P_{m}=P_{\text {loss }}+P_{d} \\
\sum_{j=1}^{N_{c}} H_{j}^{c}+\sum_{k=1}^{N_{k}} H_{k}^{h}=H_{d}
\end{gathered}
$$

where $P_{d}$ and $H_{d}$ represent the total electricity and heat energy demands, respectively.

\subsubsection{Inequality Constraints}

In order to guarantee a feasible operation, the energy output of each unit should be limited within its lower and upper bounds:

$$
\begin{gathered}
P_{i, \text { min }}^{p} \leq P_{i}^{p} \leq P_{i, \text { max }}^{p} i=1,2, \ldots, N_{P} \\
0 \leq P_{w w t, l} \leq P_{w w, \text { rate }} l=1,2, \ldots, N_{l} \\
0 \leq P_{p v, m} \leq P_{p v, \text { rate }} m=1,2, \ldots, N_{m} \\
H_{k, \text { min }}^{h} \leq H_{k}^{h} \leq H_{k, \text { max }}^{h} k=1,2, \ldots, N_{k} \\
P_{j, \text { min }}^{c}\left(H_{j}^{c}\right) \leq P_{j}^{c}\left(H_{j}^{c}\right) \leq P_{j, \text { max }}^{c}\left(H_{j}^{c}\right) j=1,2, \ldots, N_{c} \\
H_{j, \text { min }}^{c}\left(P_{j}^{c}\right) \leq H_{j}^{c}\left(P_{j}^{c}\right) \leq H_{j, \text { max }}^{c}\left(P_{j}^{c}\right) j=1,2, \ldots, N_{c}
\end{gathered}
$$

where $P_{i, \min }^{p}$ and $P_{i, \max }^{p}$ are the lower and upper bounds of the $i$ th thermal unit, respectively, $H_{k, \min }^{h}$ and $H_{k, \max }^{h}$ are the lower and upper bounds of the $k$ th heat-only unit, respectively, $P_{j, \min }^{c}\left(H_{j}^{c}\right)$ and $P_{j, \max }^{c}\left(H_{j}^{c}\right)$ are the lower and upper bounds of the jth CHP unit, respectively, and $H_{j, \min }^{c}\left(P_{j}^{c}\right)$ and $H_{j, \max }^{c}\left(P_{j}^{c}\right)$ are the lower and upper bounds of the $j$ th CHP unit, respectively.

It can be found from Equations (33) and (34) that the heat energy output of the CHP unit will directly influence its lower and upper bounds of the electricity energy output and vice versa. This coupling relationship is usually described by a feasible operating region constraint, i.e., the energy outputs of the CHP unit must be enclosed by the boundary curve ABCDEF, as illustrated in Figure 2 . The $\mathrm{BC}$ along the boundary line of the area increases the heat energy output of the unit and the electricity energy output decreases. The heat energy output by the CD unit along the line is decremented.

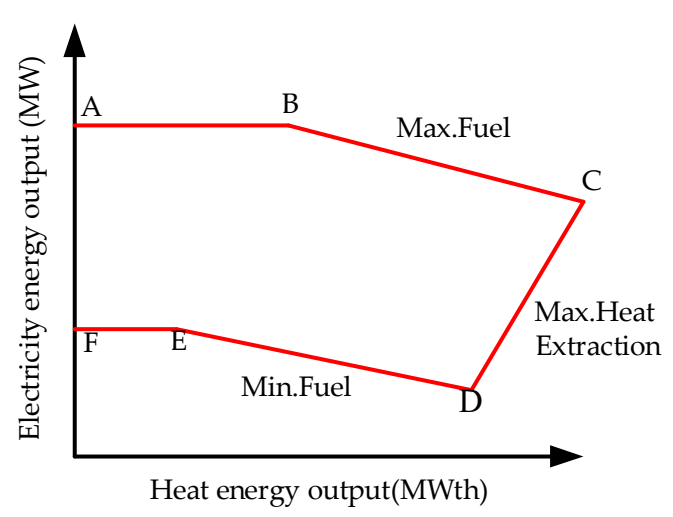

Figure 2. Feasible operation region of the combined heat and power (CHP) units. 


\section{Multi-Searcher Optimization}

Most of the existing metaheuristic algorithms are inspired by nature phenomena, and the proposed MSO is developed from their advantages and the chaos theory. Overall, the MSO consists of a two-layer searcher, in which the first-layer searcher is responsible for a wide global search and the second-layer searcher is implemented for a deep local search.

\subsection{Chaos Theory}

In many practical systems, chaos is a ubiquitous non-linear phenomenon. Chaotic motion can reach every state of a certain scale, according to its regularity and ergodicity, which is better than a simple random search. Therefore, for many optimization algorithms, chaotic theory is frequently used to introduce random parameters in the initialization solution or the replacement algorithm to enhance ergodicity and accelerate global optimal convergence [26]. Due to the non-repetitive nature of chaos, the chaotic mapping-based optimization algorithm has more comprehensive search ability than the original one. This feature can make the optimization algorithm effectively escape a low- quality local optimum and avoid the premature convergence.

Here, the logistic mapping formula is used to generate the chaotic variables with chaotic state during the initialization process, thereby, the chaotic iterative formula can be written as follows:

$$
Z_{t+1}=\kappa Z_{t}\left(1-Z_{t}\right) t=0,1,2, \ldots \kappa \in(0,4]
$$

where $Z_{t}$ is the $t$ th chaotic vector and $\kappa$ is a positive real parameter, i.e., the controllable variables of the optimization.

A $n$-dimensional chaotic vector $Z_{0}\left(Z_{0}=z_{01}, z_{02}, \ldots, z_{0 n}\right)$ is randomly generated and each component value is between 0 and 1 . On the basis of the chaotic iterative formula and the $n$-dimensional chaotic vector $Z_{0}\left(Z_{0}=z_{01}, z_{02}, \ldots, z_{0 n}\right)$, the $N$ vectors $Z_{1}\left(Z_{1}=z_{11}, z_{12}, \ldots, z_{1 n}\right), Z_{2}\left(Z_{2}=z_{21}, z_{22}, \ldots\right.$, $\left.z_{2 n}\right), \ldots, Z_{N}\left(Z_{N}=z_{N 1}, z_{N 2}, \ldots, z_{N n}\right)$ can be obtained by iteration. The chaotic vector is used for the iterative search and then the component of the chaotic vector $Z_{i}(i=1,2, \ldots, N)$ is transformed into the constraint range of Equations (29)-(32) by Equation (36), as follows:

$$
x_{i j}=x_{\min }+z_{i j} \times\left(x_{\max }-x_{\min }\right) \quad i=1,2, \ldots, N ; j=1,2, \ldots, n
$$

where $x_{\min }$ and $x_{\max }$ are the lower and upper limits of the optimization variable, respectively.

\subsection{Double Layer Searcher}

As shown in Figure 3, in the process of initialization, a series of searchers are randomly distributed within the search area by using Equation (36), which is the so-called global searcher (GS) in the MSO. Surrounded by each global searcher and centered around this searcher within a specified radius, some other searchers are randomly distributed, known as local searchers (LS), which are subject to the global searcher. These LS aims to perceive the surrounding dynamic change process in the vicinity of each GS and then perform a local search. When the searching process of the GS is finished, the LS will initiate a subsequent search. This feature can effectively improve the convergence speed and avoid a low-quality local optimum. 


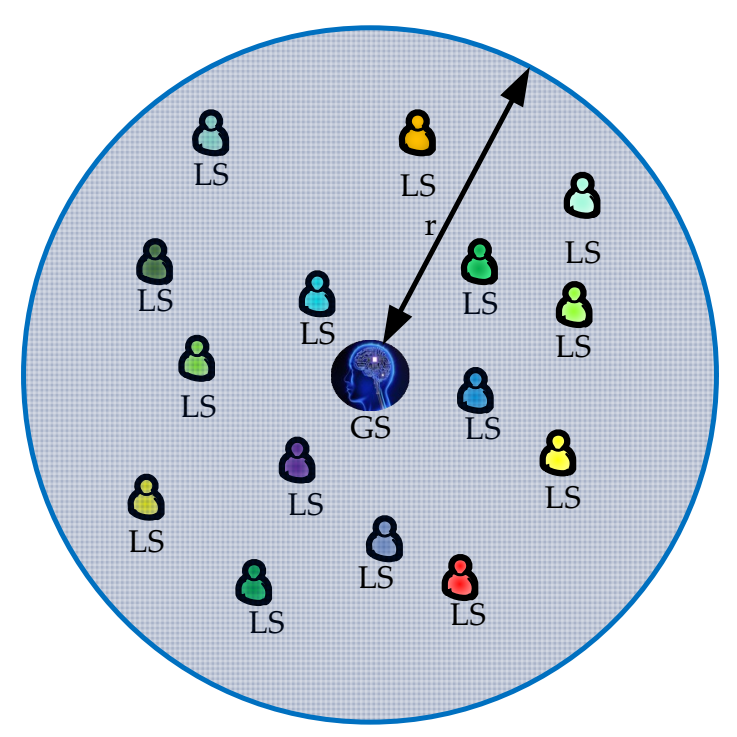

Figure 3. Double-layer searcher search area.

The search radius of the GS depends on the distance from the global best (Gbest) and the level of each global searcher. The level will be equal to 0 if a global searcher is finding the minimum cost, and vice versa. Hence, the search radius of the GS is calculated as follows:

$$
r=\max \left\{\left(r_{\max }-r_{\min }\right) \frac{k_{G S}}{n_{G S}-1}+r_{\min }, \operatorname{dist}(\mathrm{GS}, \text { Gbest })\right\}
$$

where $r_{\max }$ and $r_{\min }$ are the pre-set maximum and minimum radii, $k_{G S}$ represents the level of GS, $n_{G S}$ is the number of global searchers, Gbest is described as the global optimal solution, and dist (GS,Gbest) denotes the distance between the global searcher and the global best.

\subsection{Random Walk Rule}

As shown in Figure 4, after searching using the LS, each GS begins to move to a new position by a random motion technique called "random walk". Movement in the random walk is done from a point toward the target position, which leads to the GS being located in the area around the target position.

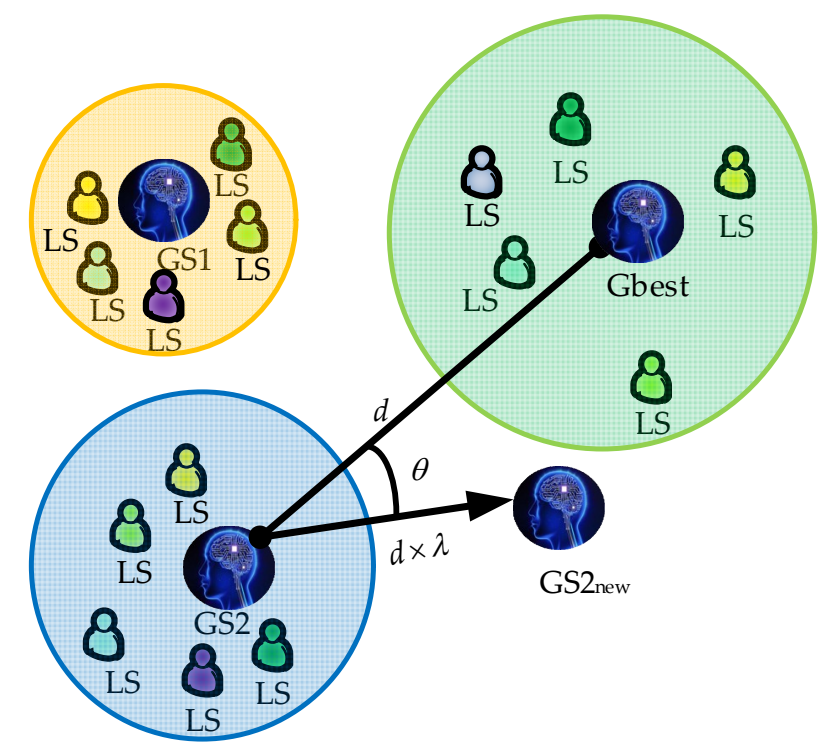

Figure 4. Random walk rule of the global searcher (GS). 
To randomly move from one position to another, the searcher should consider two variables, including the distance and direction angle. The distance is determined by a coefficient of the distance between two points, and the direction angle is a random value. The distance between the global searcher and the global best (known as $\mathrm{d}$ ) is found by using Equation (37). $\lambda$ is a random value with a distribution of uniform probability in a range from 0 to 1 , and $\theta$ is a random value with a distribution of uniform probability in a range from $-\pi / 4$ to $\pi / 4$. When all global searchers move according to the random walk rule, the new position can be obtained, and the obtained solution will be compared with the current global optimal solution. If the solution quality is higher, the global optimal solution will be replaced.

\subsection{Constraint Processing}

In this paper, all equality constraints (Equations (27)-(28)) are processed by the penalty function method to avoid the "over limit" phenomenon. The equality constraint optimization is transformed into a problem without an equality constraint, and the fitness function is constructed by using a penalty coefficient $M$, which is as follows:

$$
\begin{aligned}
C_{\text {total }} & =C_{i}\left(P_{i}^{p}\right)+C_{j}\left[P_{j}^{c}, H_{j}^{c}\right]+C_{k}\left(H_{k}^{h}\right)+C_{w t, l}\left(P_{l}\right)+C_{p v, m}\left(P_{m}\right) \\
& +\mathrm{M}\left|P_{i}^{p}+P_{j}^{c}+P_{l}+P_{m}-P_{l o s s}-P_{d}\right|+M\left|H_{j}^{c}+H_{k}^{h}-H_{d}\right|
\end{aligned}
$$

Moreover, the penalty factor $M$ is used for guaranteeing a feasible solution for the proposed OED. In general, a larger $M$ can effectively avoid an infeasible solution, but easily results in a low optimization accuracy. Hence, the penalty factor $M$ should be carefully set via a proper balance between the constraint violation and the optimization accuracy. Through trial-and-error, it was set to be $10^{7}$ for OED. Obviously, when the equality constraint is satisfied, the penalty function is equal to 0 , and the value of the fitness function is the cost function.

\subsection{Execution Procedure}

In order to solve a specific optimization problem, the number of optimization variables, constraints, and the objective function should be given to the proposed MSO. In fact, the number of optimization variables will determine the parameters setting of the MSO, while the fitness function is completely dependent on both of the objective function and constraints. Therefore, the proposed MSO can be used for addressing different benchmark test functions or the proposed OED.

At last, the overall execution procedure of the MSO for OED is given in the Figure 5.

- Step 1: Input system parameters and unit parameters, including the operating cost coefficients of the thermal units, CHP units and heat-only units, the feasible operating region of the CHP units, and the main parameters of renewable energy resources such as wind speed and solar irradiance. Set the algorithm parameters, including the number of GS, the number of LS, the maximum search radius, minimum search radius, and the maximum iteration number.

- Step 2: Initialize the double-layer searcher based on Equations (35)-(36) in chaos theory; and set the current iteration number $\mathrm{T}=1$.

- Step 3: Determine the global searcher level and searcher radius with Equation (37). Particularly, the level 0 is assigned to the GS corresponding to the least cost, and the highest level is assigned to the GS corresponding to the highest cost.

- Step 4: Implement the global searcher and local searcher separately, where the local searcher is surrounded by each global searcher and centered around the searcher within a specified radius.

- Step 5: Calculate the objective function with Equation (15), which is equal to the total operating cost.

- Step 6: Evaluate the objective function using the penalty function method from Equation (38), based on the given $\mathrm{M}$. 
- Step 7: Determine the distance and direction based on random walk theory and guide global searcher migration, in which both $\lambda$ and $\theta$ are the random values with a distribution of uniform probability.

- Step 8: Judge the termination of MSO. If the termination condition is met, then output the economic scheduling result, else turn to step 3 and enter the next iteration.

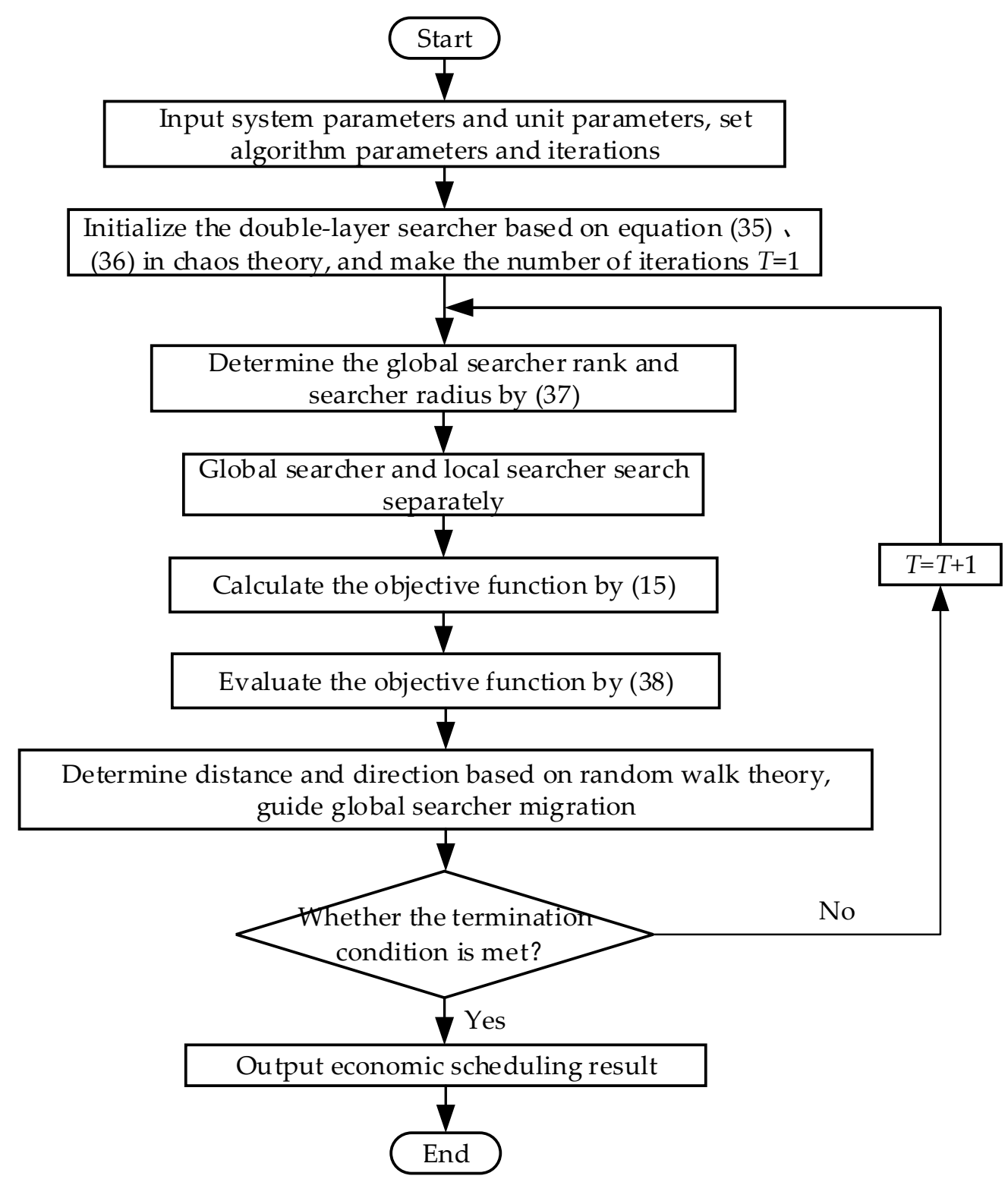

Figure 5. Execution procedure of the multi-searcher optimization (MSO) for optimal energy dispatch (OED).

\section{Case Studies}

In order to test the optimization effect of the MSO for the OED of combined heat and power-thermal-wind-photovoltaic systems, this paper introduces nine commonly used heuristic algorithms which are highly independent from a specific mathematical model, including biogeography-based optimization (BBO) [27], cultural algorithms (CA) [28], firefly algorithms (FA) [29], genetic algorithms (GA) [11], the grey wolf optimizer (GWO) [14], moth-flame optimization (MFO) [30], particle swarm optimization (PSO) [12], simulated annealing (SA) [31] and a teach-learn based optimization algorithm (TLBO) [32]. 
Through trial-and-error, the main parameters of different algorithms are given in Table 1. All the simulations were undertaken in MATLAB R2016b on a personal computer with an Intel(R) Core TM i7 CPU at $3.4 \mathrm{GHz}$ with $16 \mathrm{~GB}$ of RAM.

Table 1. Summary of the most important parameters used for different algorithms.

\begin{tabular}{|c|c|c|}
\hline Algorithm & Parameter & Value \\
\hline \multirow{3}{*}{$\mathrm{BBO}$} & Number of habitats & 150 \\
\hline & Keep rate & 0.2 \\
\hline & Mutation & 0.1 \\
\hline \multirow{2}{*}{ CA } & Population size & 150 \\
\hline & Acceptance ratio & 0.35 \\
\hline \multirow{5}{*}{ FA } & Number of fireflies & 150 \\
\hline & Light absorption coefficient & 1 \\
\hline & Attraction coefficient base value & 2 \\
\hline & Mutation coefficient & 0.2 \\
\hline & Mutation coefficient damping ratio & 0.98 \\
\hline \multirow{4}{*}{ GA } & Population size & 150 \\
\hline & Mutation probability & 0.1 \\
\hline & Crossover probability & 0.75 \\
\hline & Generation gap & 0.8 \\
\hline GWO & Population size & 150 \\
\hline MFO & Total number of moths & 150 \\
\hline \multirow{4}{*}{ PSO } & Inertia weight & 1 \\
\hline & Inertia weight damping ratio & 0.99 \\
\hline & Personal learning coefficient & 1.5 \\
\hline & Global learning coefficient & 2.0 \\
\hline \multirow{5}{*}{ SA } & Maximum number of sub-iterations & 20 \\
\hline & Initial temp. & 0.1 \\
\hline & Temp. reduction rate & 0.99 \\
\hline & Number of neighbors per individual & 5 \\
\hline & Mutation rate & 0.5 \\
\hline TLBO & Population size & 150 \\
\hline \multirow{4}{*}{ MSO } & Number of global searchers & 150 \\
\hline & Number of local searchers & 30 \\
\hline & Maximum search radius & 1.414 \\
\hline & Minimum search radius & $1 \mathrm{e}-4$ \\
\hline
\end{tabular}

In order to assure a fair comparison, all the parameters of each algorithm have been carefully set based on two rules, as follows:

(1) Common parameters: The maximum iteration number and the population size are the common parameters of all of the algorithms, which should be set to the same values for each algorithm. Generally speaking, both a larger maximum iteration number and a larger population size can effectively obtain a higher quality optimum, however, this consumes more computation time. Hence, these two parameters were set to achieve a proper balance between the optimum quality and the computation time. Through trial-and-error, they were set to be 300 and 150 for all the algorithms, respectively.

(2) Independent parameters: Each algorithm has its own parameters, e.g., the crossover probability of GA and the maximum velocity of PSO. These parameters can be determined according to the optimum quality with the given maximum iteration number and population size. Through trial-and-error, the optimal parameters are given in Table 1. 


\subsection{Benchmark Test Function}

In order to verify the validity of the algorithm, three different types of functions were selected for numerical experiments. The number of iteration steps was set to 100 .

The Sphere function is a simpler unimodal function that examines the convergence speed of the algorithm, where the mathematical model can be written as follows:

$$
\min f(x)=\sum_{i=1}^{n} x_{i}{ }^{2}, n=2,\left|x_{i}\right| \leq 5.12
$$

The global advantage is $x_{i}=0, f(x)=0$. The comparison of the fitness convergence curves in the unimodal function is shown in the Figure 6. It can be seen that the MSO can converge to the global optimum with a fastest convergence rate compared to the other nine algorithms.

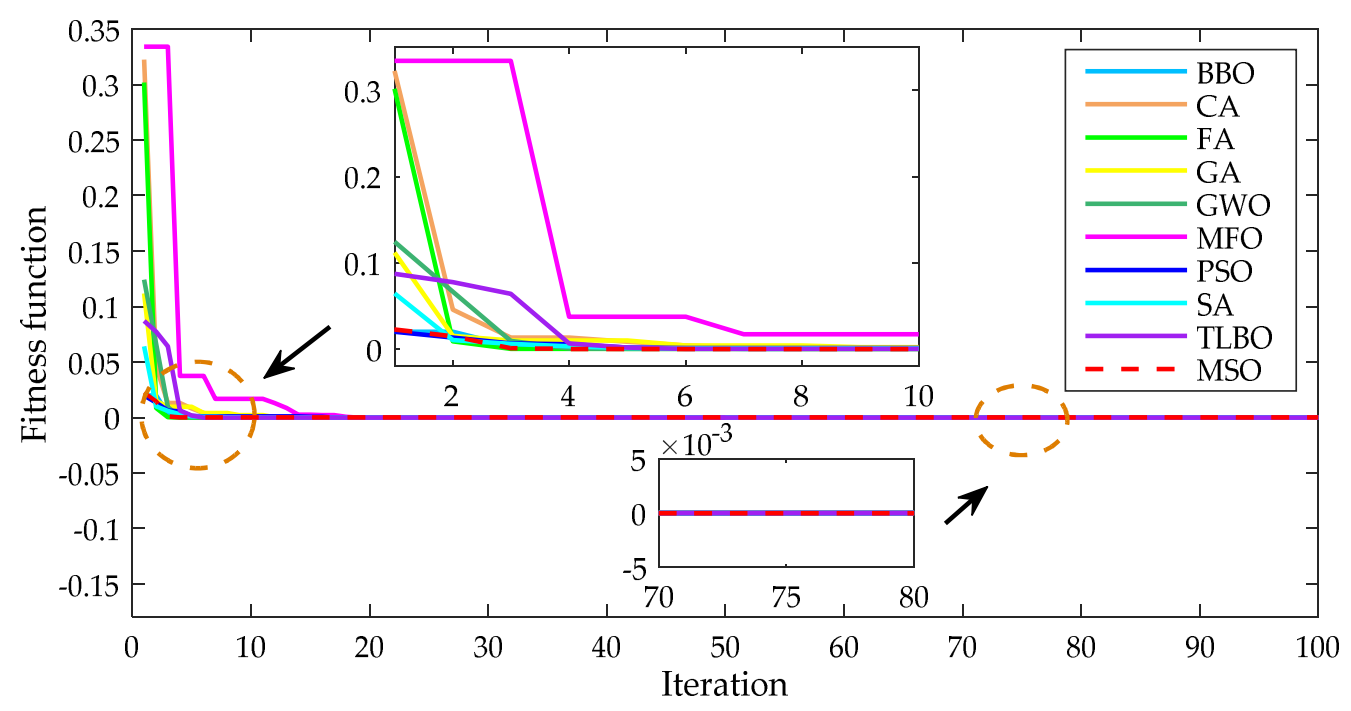

Figure 6. Comparison of convergence curves of ten algorithms in single peak test function.

The step function is a discontinuous step function that can be used to verify the validity of the algorithm, which can be described as follows:

$$
\min f(x)=\sum_{i=1}^{n}\left(x_{i}+0,5\right)^{2}, n=5,\left|x_{i}\right| \leq 10
$$

The global best advantage is $x_{i}=0, f(x)=0$. The comparison results of the fitness convergence curves of the discontinuous step function are shown in the Figure 7. Similarly, the proposed MSO also had the fastest convergence rate among all of the algorithms, while a global optimum could be guaranteed.

The Rastrigin function is a multimodal function that can be used to test the algorithm's ability to jump out of local optimum, which can be described as follows:

$$
\min f(x)=10 n+\sum_{i=1}^{n} x_{i}^{2}-10 \cos \left(2 \pi x_{i}\right), n=2,\left|x_{i}\right| \leq 5.12
$$

The global best advantage is $x_{i}=0, f(x)=0$. The comparison results of the fitness convergence curves of the discontinuous step function are shown in the Figure 8. It can be seen that the global optimization ability of the MSO was more obvious, and other comparison algorithms were trapped in a low-quality local optimum. 


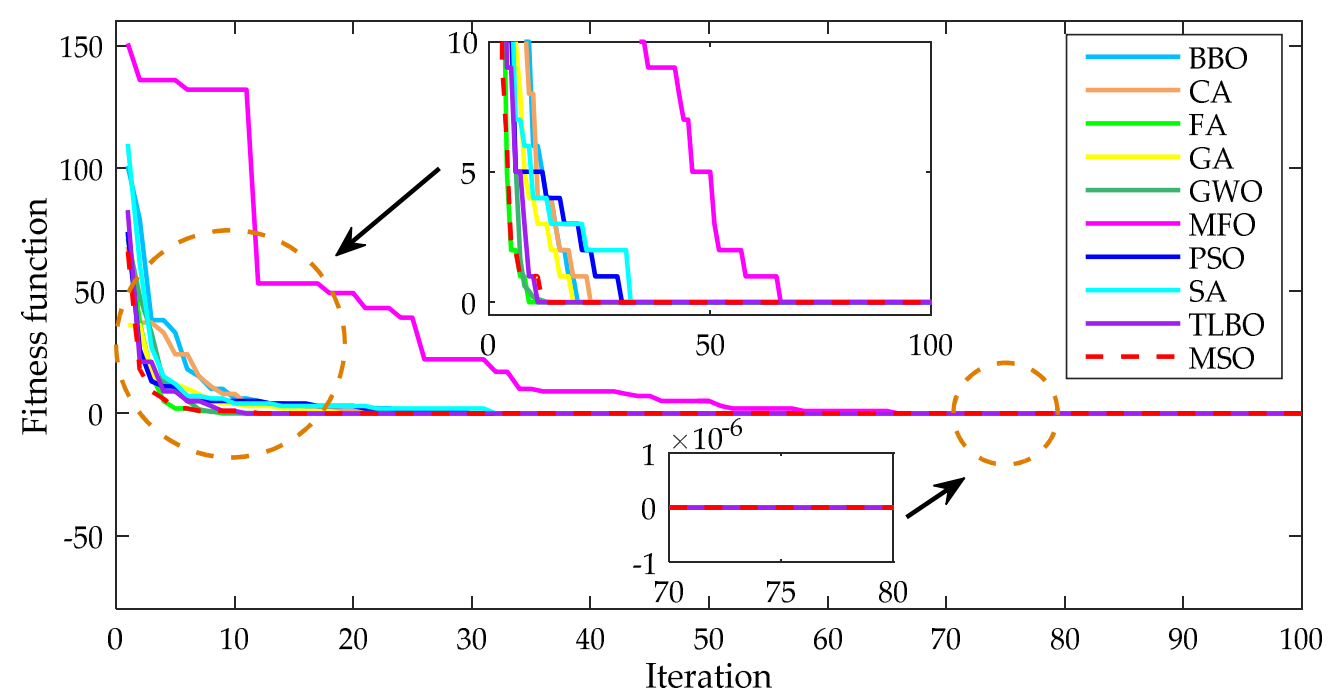

Figure 7. Comparison of convergence curves of ten algorithms in a discontinuous step test function.

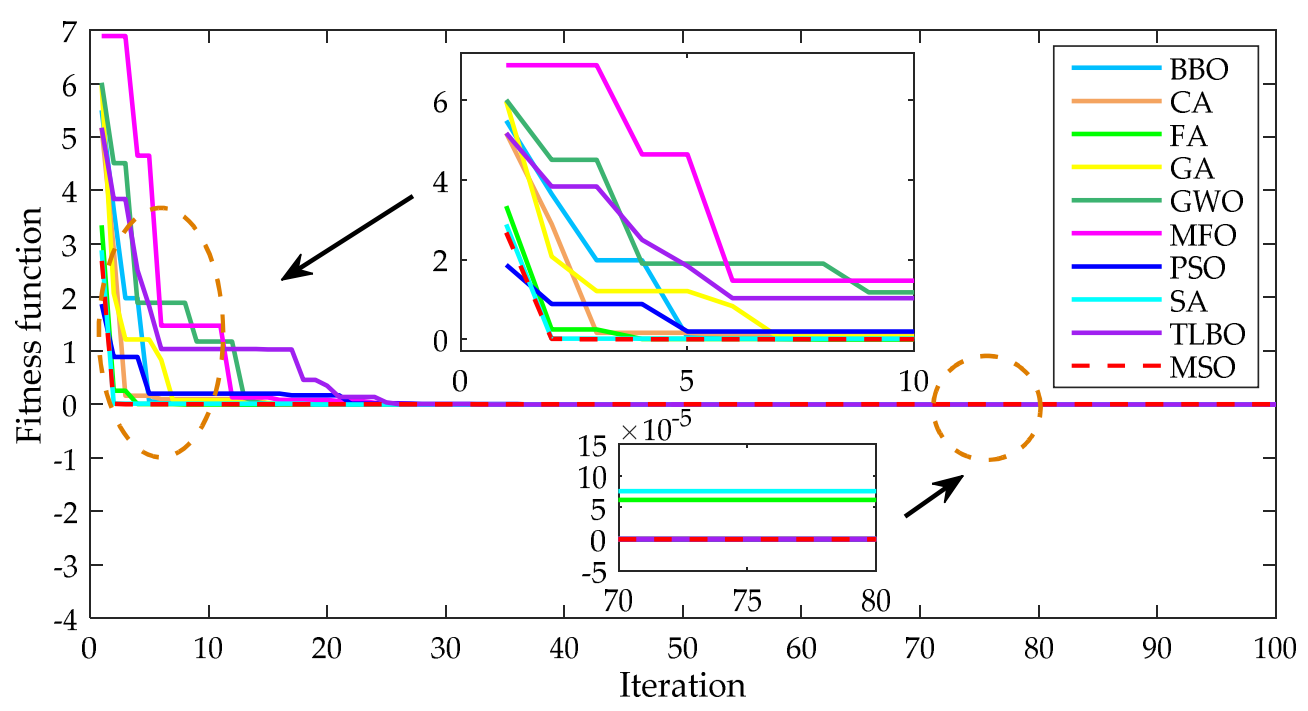

Figure 8. Comparison of convergence curves of ten algorithms in multi-peak test function.

In the figures (like Figure 6), the MSO seems to have an advantage immediately in iteration 0 or 1. The main reason for this is that the MSO adopts chaotic mapping for the population initialization, which can reach every state of a certain scale due to its regularity and ergodicity. On the other hand, the other algorithms only adopt a simple random search-based initialization, such that they easily lead to a low optimization efficiency during the initialization process. Hence, the MSO can effectively obtain a higher quality initial best solution compared to other algorithms.

\subsection{Simulation Model}

The test system included 13 thermal units with the valve point effect, $4 \mathrm{CHP}$ units, 4 heat-only units, 3 WT units and 3 PV units. The proposed OED was implemented as a day-ahead or hour-ahead dispatch, thereby the demand profile was determined by the day-ahead or hour-ahead load forecasting according to the historical demand data [33-35]. The total electricity energy demand was $3837.136 \mathrm{MW}$ and total heat energy demand was 615.372MWth.

The main parameters of the thermal units, CHP units and heat-only units are provided in Tables 2-4, respectively. The feasible operating region of the CHP unit is shown in Figure 9. The main parameters of renewable energy resources are given in Table 5. All the parameters of the energy 
sources are steady values, which are usually acquired from the energy suppliers when they connect into the integrated energy system. In this paper, these parameters were referred from the published papers $[18,36-40]$. The capacities of the WT units in these papers were $130 \mathrm{MW}, 94 \mathrm{MW}$ and $94 \mathrm{MW}$, respectively. Moreover, the capacity of the PV unit was $150 \mathrm{MW}$, separately. The maximum iteration number of each algorithm was set to 300 .

Table 2. Parameters of thermal units.

\begin{tabular}{cccccccc}
\hline \multirow{2}{*}{ Unit No. } & \multirow{2}{*}{$\begin{array}{c}\text { Minimum } \\
\text { (MW) }\end{array}$} & \multirow{2}{*}{$\begin{array}{c}\text { Maximum } \\
\text { (MW) }\end{array}$} & \multicolumn{5}{c}{ Operating Cost Coefficients } \\
\cline { 4 - 7 } & & 75 & 0.008 & 2 & 25 & 100 & 0.042 \\
G1 & 10 & 125 & 0.003 & 1.8 & 60 & 140 & 0.04 \\
G2 & 20 & 175 & 0.0012 & 2.1 & 100 & 160 & 0.038 \\
G3 & 30 & 250 & 0.001 & 2 & 120 & 180 & 0.037 \\
G4 & 40 & 680 & 0.00028 & 8.1 & 550 & 300 & 0.035 \\
G5 & 0 & 360 & 0.00056 & 8.1 & 309 & 200 & 0.042 \\
G6 & 0 & 360 & 0.00056 & 8.1 & 309 & 200 & 0.042 \\
G7 & 0 & 180 & 0.000324 & 7.74 & 240 & 150 & 0.063 \\
G8 & 60 & 180 & 0.000324 & 7.74 & 240 & 150 & 0.063 \\
G9 & 60 & 120 & 0.00284 & 8.6 & 126 & 100 & 0.084 \\
G10 & 40 & 120 & 0.00284 & 8.6 & 126 & 100 & 0.084 \\
G11 & 40 & 120 & 0.00284 & 8.6 & 126 & 100 & 0.084 \\
G12 & 55 & 120 & 0.00284 & 8.6 & 126 & 100 & 0.084 \\
G13 & 55 & & & & & & \\
\hline
\end{tabular}

Table 3. Parameters of CHP units.

\begin{tabular}{cccccccc}
\hline \multirow{2}{*}{ Unit No. } & $\begin{array}{c}\text { Feasible Region } \\
\text { Number }\end{array}$ & \multicolumn{6}{c}{ Operating Cost Coefficients } \\
\cline { 3 - 7 } & & $\mathbf{a}$ & $\mathbf{b}$ & $\mathbf{c}$ & $\mathbf{d}$ & $\mathbf{e}$ & $\mathbf{f}$ \\
\hline CHP1 & \#A & 0.0345 & 14.5 & 0.03 & 4.2 & 0.031 & 2650 \\
CHP2 & \#B & 0.0435 & 36 & 0.027 & 0.6 & 0.011 & 1250 \\
CHP3 & \#C & 0.1035 & 34.5 & 0.025 & 2.203 & 0.051 & 2650 \\
CHP4 & \#D & 0.072 & 20 & 0.02 & 2.34 & 0.04 & 1565 \\
\hline
\end{tabular}

Table 4. Parameters of heat-only units.

\begin{tabular}{cccccc}
\hline \multirow{2}{*}{ Unit No. } & $\begin{array}{c}\text { Minimum } \\
\text { (MWth) }\end{array}$ & $\begin{array}{c}\text { Maximum } \\
\text { (MWth) }\end{array}$ & \multicolumn{3}{c}{ Operating Cost Coefficients } \\
\cline { 4 - 5 } & & & $\mathbf{a}$ & $\mathbf{b}$ & $\mathbf{c}$ \\
\hline H1 & 0 & 60 & 0.038 & 2.0109 & 950 \\
H2 & 0 & 120 & 0.038 & 2.0109 & 950 \\
H3 & 0 & 120 & 0.052 & 3.0651 & 480 \\
H4 & 0 & 0.052 & 3.0651 & 480 \\
\hline
\end{tabular}




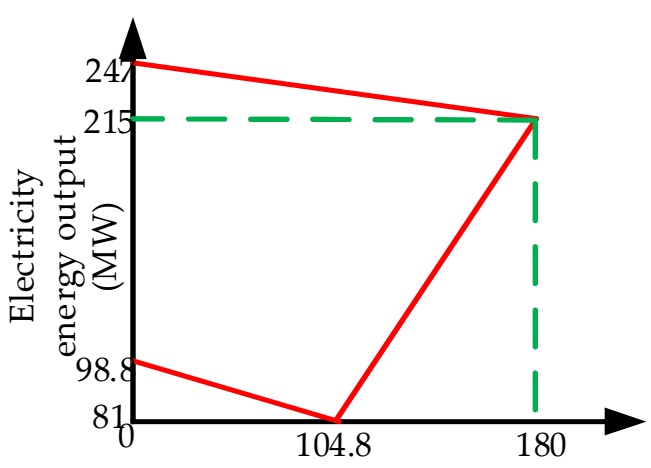

Heat energy output(MWth)

\#A

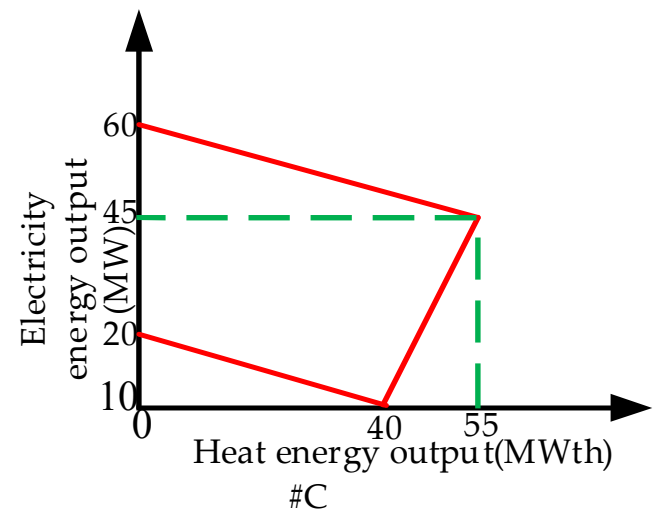

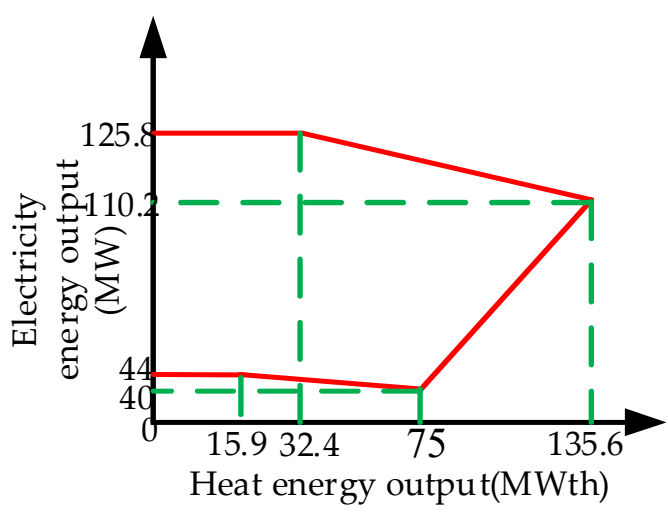

\#B

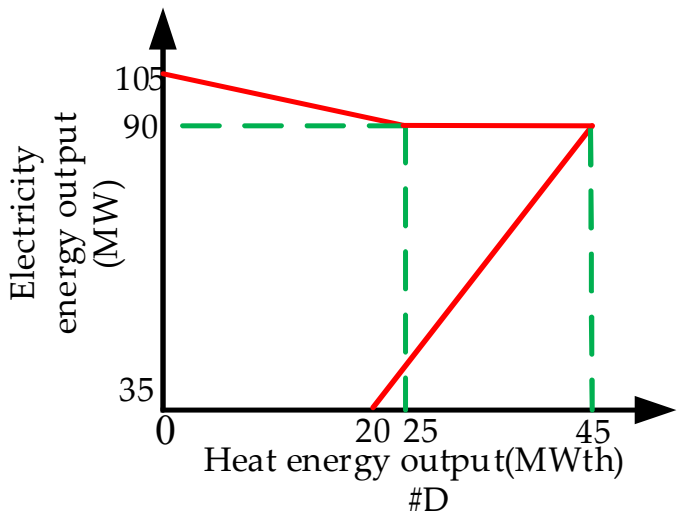

Figure 9. Feasible operation region of the $\mathrm{CHP}$ unit.

Table 5. Parameters of renewable energy resources.

\begin{tabular}{ccccccccc}
\hline \multirow{2}{*}{ WT } & $k$ & $c$ & $v_{\text {in }}$ & $v_{\text {out }}$ & $v_{r}$ & $d_{w w t, l}$ & $K_{u e, w t, l}$ & $K_{o e, w t, l}$ \\
& 2 & 15 & $15 \mathrm{~m} / \mathrm{s}$ & $45 \mathrm{~m} / \mathrm{s}$ & $5 \mathrm{~m} / \mathrm{s}$ & $120 \$ / \mathrm{MWh}$ & $15 \$ / \mathrm{MWh}$ & $20 \$ / \mathrm{MWh}$ \\
\hline \multirow{2}{*}{$\mathbf{P V}$} & $k$ & $c$ & $A$ & $\eta$ & $r_{m a x}$ & $d_{p v, m}$ & $K_{u e, p v, m}$ & $K_{o e, p v, m}$ \\
& 0.95 & 0.95 & $80,000 \mathrm{~m}^{2}$ & $14 \%$ & $700 \mathrm{~W} / \mathrm{m}^{2}$ & $200 \$ / \mathrm{MWh}$ & $15 \$ / \mathrm{MWh}$ & $20 \$ / \mathrm{MWh}$ \\
\hline
\end{tabular}

\subsection{Discussion and Analysis}

Figure 10 shows the convergence of total operating costs obtained by different algorithms and the detailed optimal dispatch strategies of all the energy suppliers obtained by different algorithms are listed in Table 6. It can be seen that the MSO obtains the lowest total operating cost, which can verify that the MSO can effectively jump out of a low-quality local optimum. The MSO started to converge after 114 iterations. 


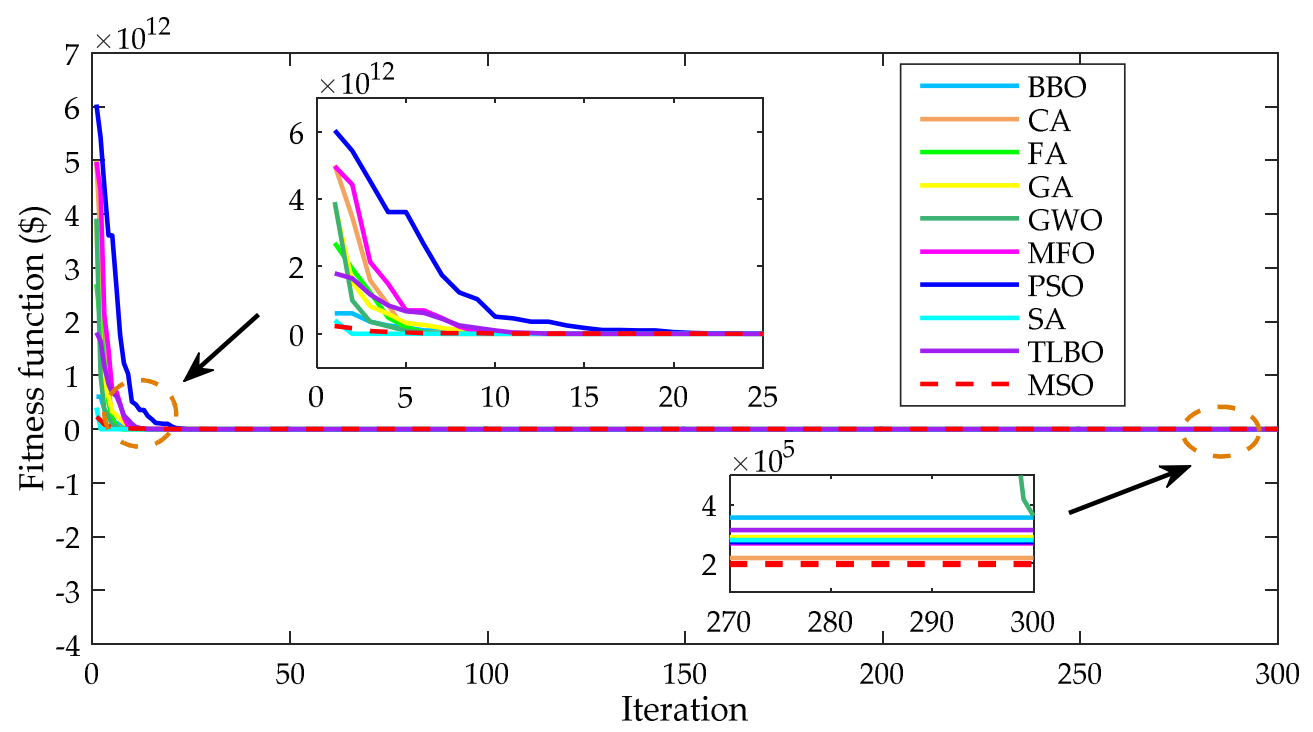

Figure 10. Convergence process of a total operating costs obtained by different algorithms.

Table 6. Comparative results of optimal solutions obtained by different algorithms.

\begin{tabular}{|c|c|c|c|c|c|c|c|c|c|c|c|}
\hline \multirow{2}{*}{ Type } & \multirow{2}{*}{ Output } & \multicolumn{10}{|c|}{ Optimal Energy Generations and Consumptions } \\
\hline & & ВВО & CA & FA & GA & GWO & MFO & PSO & SA & TLBO & MSO \\
\hline Power & P1(MW) & 63.9199 & 50.2982 & 32.8433 & 74.2171 & 25.4700 & 69.8638 & 69.6133 & 53.7707 & 75 & 72.9133 \\
\hline Power & P2(MW) & 113.3121 & 124.1695 & 124.8105 & 109.0534 & 115.3113 & 124.9997 & 78.8729 & 100.9643 & 125 & 121.5222 \\
\hline Power & P3(MW) & 147.0970 & 174.5121 & 135.2467 & 174.8051 & 163.9012 & 174.9704 & 174.5487 & 168.9912 & 167.0758 & 174.8046 \\
\hline Power & P4(MW) & 234.7876 & 246.0860 & 248.6721 & 249.7978 & 245.4024 & 250 & 249.7967 & 248.8495 & 250 & 246.8026 \\
\hline Power & P5(MW) & 678.6543 & 680 & 676.4627 & 632.1365 & 678.0293 & 680 & 672.4073 & 679.7625 & 678.3858 & 678.1835 \\
\hline Power & P6(MW) & 353.4480 & 356.1580 & 347.8350 & 345.8947 & 354.9882 & 360 & 353.9936 & 334.3117 & 359.0481 & 207.6681 \\
\hline Power & P7(MW) & 346.9123 & 358.2707 & 359.5087 & 347.0761 & 351.3845 & 354.3039 & 359.1757 & 357.7283 & 336.4010 & 359.3603 \\
\hline Power & P8(MW) & 158.9928 & 179.7758 & 149.0258 & 172.9118 & 179.8825 & 180 & 174.0666 & 174.3501 & 154.0664 & 133.1413 \\
\hline Power & P9(MW) & 160.8106 & 176.7479 & 179.8817 & 149.3145 & 160.4787 & 180 & & 152.6315 & 148.5617 & 179.6216 \\
\hline Power & P10(MW) & 111.1568 & 110.93 & 119.7094 & 112.18 & 96.9748 & 40.5 & 68.8161 & 114.0 & 116.1228 & 119.7769 \\
\hline Power & P11(MW) & 102.1842 & 114.93 & 119.9975 & 119.4566 & 113.21 & 119.6362 & 103.8 & 110.0 & 111.6787 & 119.5531 \\
\hline Power & P12(MW) & 104.8899 & 115.0328 & 118.9527 & 83.5559 & 100.2694 & 120 & 113.1716 & 104.4521 & 111.4735 & 94.3322 \\
\hline Power & P13(MW) & 106.8717 & 118.2986 & 114.2327 & 114.0840 & 119.3736 & 89.8493 & 119.3128 & & 119.3451 & 119.8543 \\
\hline $\mathrm{CHP}$ & P1(MW) & 216.2329 & 214.9459 & 201.2094 & 217.5942 & 190.6078 & & & & 209.6084 & \\
\hline CHP & P2(MW) & 109.3852 & 121.3602 & 125.7600 & 114.4708 & 125.2795 & 125.8000 & 124.2405 & 112.4446 & 125.8000 & 125.7079 \\
\hline CHP & P3(MW) & 47.4780 & 53.8661 & 45.0250 & 52.1900 & 52.5267 & 21.8770 & 47.1903 & 48.6115 & 37.9819 & 47.2630 \\
\hline CHP & P4(N & & & & & & 105 & & & 83.5980 & \\
\hline CHP & H1(MWth) & 154.0902 & 105.8885 & 137.2843 & 160.1196 & 159.2691 & 145.1058 & 169.4321 & 136.2003 & 174.9980 & 174.9259 \\
\hline CHP & H2(MWth) & 106.9527 & 92.6726 & 134.2239 & 91.5831 & 125.2321 & 135.6000 & 124.8527 & 135.2694 & 118.0129 & 134.8678 \\
\hline CHP & H3(MWth) & 16.0218 & 53.6726 & 53.7538 & 10.5961 & 25.9293 & 22.8804 & 22.1764 & 39.4864 & 0 & 46.5418 \\
\hline $\mathrm{CHP}$ & H4(MWth) & 21.5980 & & 24.3441 & 36.1383 & 44.5992 & 0 & 22.9493 & 3.2973 & 40.5366 & 13.9497 \\
\hline Heat & H1(MWth) & 42.1456 & 57.7742 & 0.0037 & 43.8526 & 59.4136 & 49.1198 & 51.9038 & 35.5999 & 57.1123 & 51.4381 \\
\hline Heat & H2(MWth) & 52.2251 & 58.2197 & 53.8983 & 41.4130 & 2.0371 & 60 & 34.9737 & 53.6162 & 34.3344 & 20.0704 \\
\hline Heat & H3(MWth) & 114.3246 & 109.4519 & 114.8345 & 113.3593 & 113.5565 & 120 & 106.5802 & 111.6646 & 118.4561 & 54.0932 \\
\hline Heat & H4(MWth) & 108.0201 & 119.4701 & 97.0291 & 118.3100 & 85.3231 & 82.6663 & 82.5075 & 100.2394 & 71.9065 & 119.4848 \\
\hline WT & P1(MW) & 100.0860 & 42.3449 & 105.3791 & 94.0481 & 107.5722 & 47.8285 & 99.7987 & 81.8546 & 116.7154 & 127.5110 \\
\hline WT & P2(MW) & 89.3316 & 54.7974 & 54.5304 & 82.8050 & 89.8558 & 94 & 60.8604 & 81.8527 & 21.7147 & 87.8778 \\
\hline WT & P3(MW) & 85.4007 & 57.7908 & 93.4421 & 84.6737 & 62.4906 & 57.8187 & 76.7202 & 82.9566 & 89.6349 & 93.6118 \\
\hline PV & & 137.7660 & 142.5187 & 149.6020 & 149.8539 & 143.1868 & 135.5707 & 123.4468 & 144.2468 & 144.4494 & 134.6146 \\
\hline PV & P2(MW) & 150 & 132.3192 & 115.4219 & 134.2294 & 126.8566 & 144.9157 & 141.7140 & 141.8942 & 116.0735 & 132.8002 \\
\hline PV & P3(MW) & 131.2980 & 143.1461 & 130.8457 & 133.2559 & 144.5088 & 147.7147 & 147.7397 & 132.3366 & 139.4303 & 148.0817 \\
\hline \multicolumn{2}{|c|}{$\operatorname{Cost}\left(\times 10^{5} \$\right)$} & 3.0549 & 2.1744 & 2.8696 & 2.8930 & 3.0038 & 2.6722 & 2.7204 & 2.7844 & 3.1342 & 1.9655 \\
\hline
\end{tabular}

Figure 11 represents the box and whisker plots of various algorithms that were ran ten times. From the comparison of the box and whisker diagrams, it can be found that the convergence stability of the MSO was not as good as GA and GWO, but the range of variation was still acceptable, and the fitness function was lower than that of GA and GWO. 


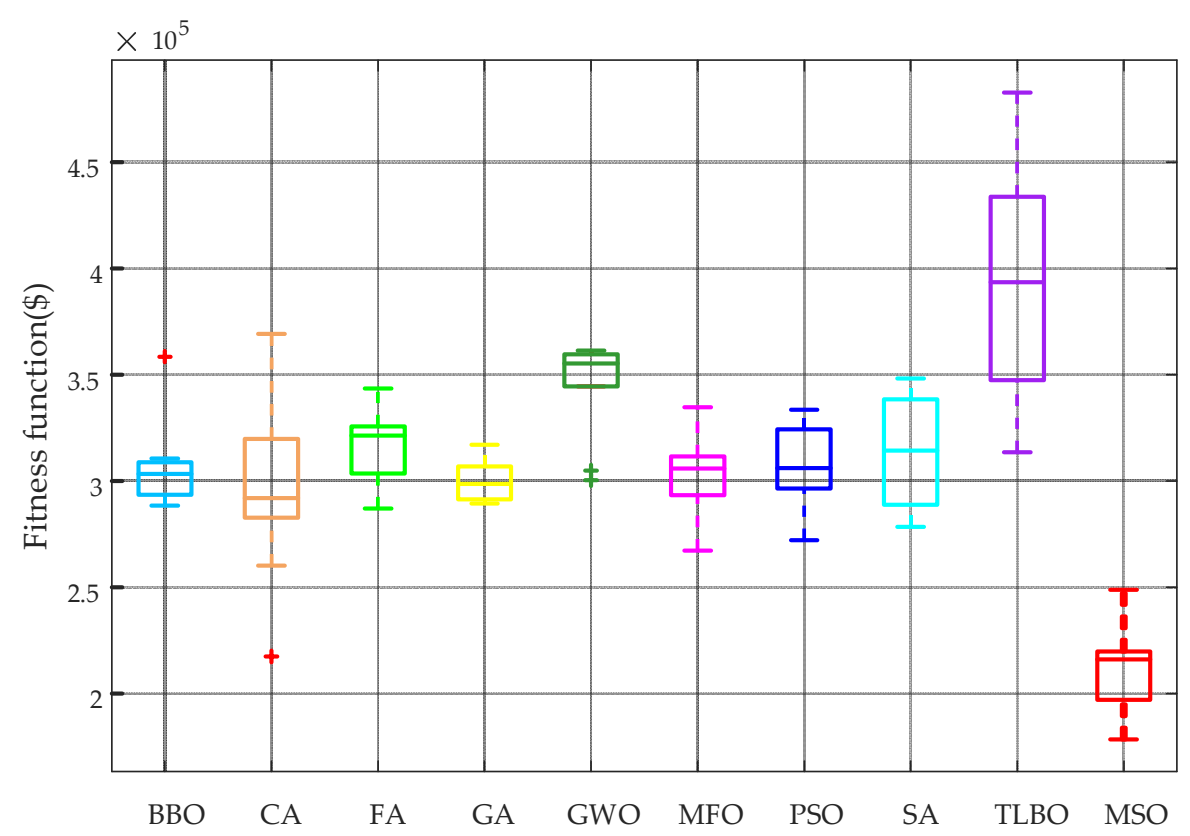

Figure 11. Box and whisker plots of total operating costs obtained by ten algorithms in 10 runs.

In order to verify the calculation speed of the MSO, Figure 12 shows the average execution time comparison bar graph, obtained by running the various algorithms 10 times. It was found that the execution time of MSO was the shortest among all the algorithms, which was about 4.96 times faster than SA.

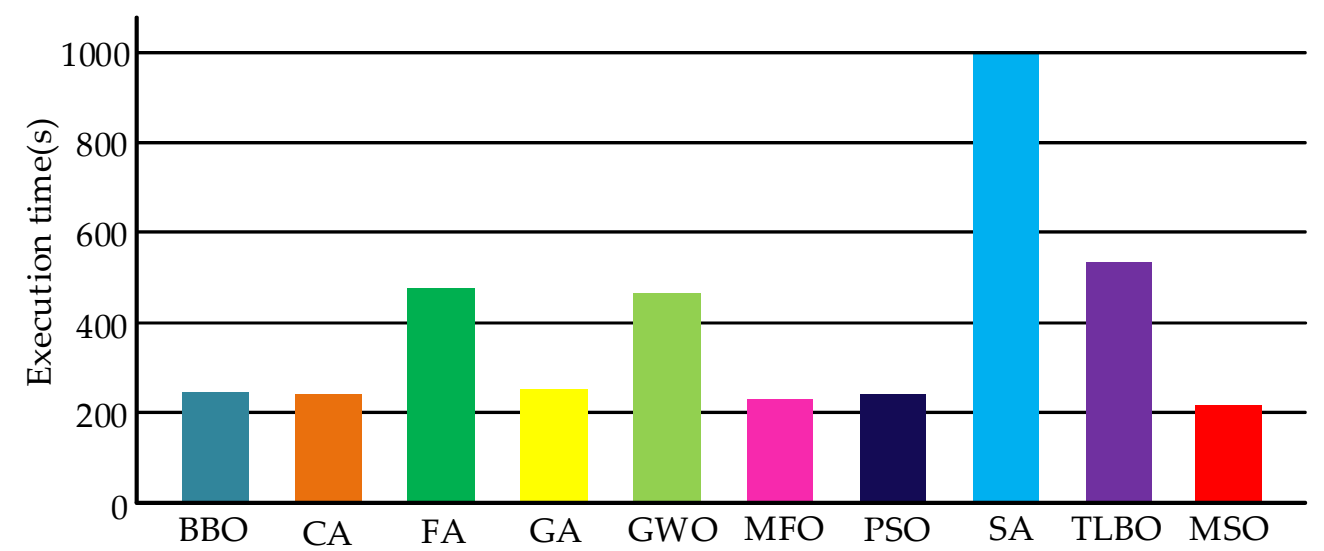

Figure 12. Average execution time obtained by ten algorithms in 10 runs.

\section{Conclusions}

In this paper, a novel MSO is proposed for the OED of combined heat and power-thermal-windphotovoltaic systems, which has the following advantages:

1. The introduction of chaos theory can effectively maintain the non-repetition of the initial population and the diversity of the searcher, which can improve the global search ability of MSO.

2. The double-layer searcher can effectively make the proposed MSO quickly converge to the best advantage, and avoid the defects that cause the traditional heuristic algorithm to easily fall into a low-quality local optimum.

3. The superior performance of the MSO was verified by the benchmark test function and a specific engineering optimization of $\mathrm{OED}$, compared with various heuristic algorithms. 
The next research work will integrate the migration learning into the MSO reasonably, and consider the actual loss of the network, and apply it to a more complex optimization.

Author Contributions: Methodology, X.Z.; Investigation, J.C.; Data curation, Z.L.; Formal analysis, J.T.; Writing—original draft preparation, J.T.; Writing—review and editing, X.Z.; Supervision, T.Y.

Funding: This research was funded by the National Natural Science Foundation of China (Grant. 51477055 \& 51777078).

Acknowledgments: The authors gratefully acknowledge the support of the National Natural Science Foundation of China.

Conflicts of Interest: The authors declare no conflict of interest.

\section{Nomenclature}

ED

IES

WT

PV

OMEF

MABL

EHED

MECS

OED

GA

PSO

DE

GWO

MSO

CHP

GS

LS

$\mathrm{BBO}$

CA

FA

MFO

SA

TLBO

V

v

$k$

$c$

$p_{w t}$

$p_{w t}^{r}$

$v_{r}$

$v_{\text {in }}, v_{\text {out }}$

$P_{\text {WT }}$

$r_{\text {max }}$

$r$

A

$p_{p v}$

$p_{p v}^{\max }$

$C_{i}\left(P_{i}^{p}\right)$

$C_{j}\left[P_{j}^{c}, H_{j}^{c}\right]$
Economic dispatch

Integrated energy system

Wind turbine

Photovoltaic

Optimal multi-energy flow

Multi-agent bargaining learning

Energy hub economic dispatch

Multiple energy carrier systems

Optimal energy dispatch

Genetic algorithm

Particle swarm optimization

Differential evolution

Grey wolf optimizer

Multi-searcher optimization

Combined heat and power

Global searcher

Local searcher

Biogeography-based optimization

Cultural algorithm

Firefly algorithm

Moth-flame optimization

Simulated annealing

Teach-learn based optimization algorithm

Speed random variable

Wind speed

Shape factor of the wind speed probability distribution function

Scale factor of the wind speed probability distribution function

Current maximum power points of wind turbines unit

Rated power of WT unit

Rated wind speed

Cut-in and cut-out wind speeds, respectively

Wind power random variable

Maximum solar irradiance

Solar irradiance

Total area of the photovoltaic cell

Output power of a PV cell

Maximum generated power

Cost function of the $i$ th thermal unit

Cost function of the $j$ th CHP 


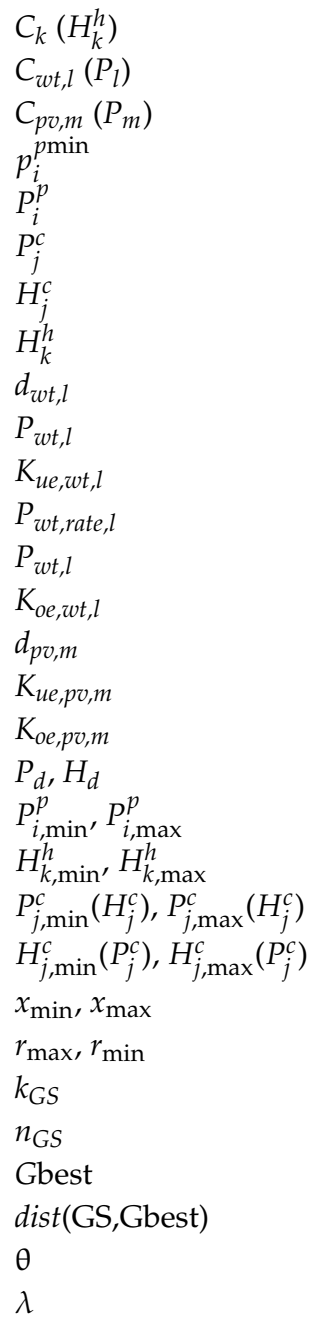

Cost function of the $k$ th heat-only unit

Cost function of the lth WT unit

Cost function of the $m$ th PV unit

Minimum power generation limit of the $i$ th thermal unit

Electricity energy output of the $i$ th thermal unit

Electricity energy output of the $j$ th CHP unit

Heat energy output of the $j$ th CHP unit

Heat energy output of the $k$ th heat-only unit

Direct cost coefficients of the $l$ th wind power

Electricity energy output of the $l$ th wind power

Underestimated coefficient of the $l$ th wind power

Rated power generation of the $l$ th wind power

Scheduled power generation of the $l$ th wind power

Overestimated coefficient of the $l$ th wind power

Direct cost coefficients of the $m$ th PV power unit

Underestimated coefficient of the $m$ th PV unit

Overestimated coefficient of the $m$ th PV unit

Total electricity and heat energy demands, respectively

Lower and upper bounds of the $i$ th thermal unit, respectively

Lower and upper bounds of the $k$ th heat-only unit, respectively

Lower and upper bounds of the $j$ th CHP unit, respectively

Lower and upper bounds of the $j$ th CHP unit, respectively

Lower and upper limits of the optimization variable, respectively

Pre-set maximum and minimum radius

Level of GS

Number of global searchers

Global optimal solution

Distance between the global searcher and the global best

Direction angle

Random value with a distribution of uniform probability in the range of $0-1$

\section{References}

1. Li, Y.-S.; Zhang, H.-G.; Huang, B.-N.; Teng, F. Distributed Optimal Economic Dispatch Based on Multi-Agent System Framework in Combined Heat and Power Systems. Appl. Sci. 2016, 6, 308. [CrossRef]

2. Shao, C.; Ding, Y.; Wang, J.; Song, Y. Modeling and Integration of Flexible Demand in Heat and Electricity Integrated Energy System. IEEE Trans. Sustain. Energy 2018, 9, 361-370. [CrossRef]

3. Li, J.; Niu, D.; Wu, M.; Wang, Y.; Li, F.; Dong, H. Research on Battery Energy Storage as Backup Power in the Operation Optimization of a Regional Integrated Energy System. Energies 2018, 11, 2990. [CrossRef]

4. Qu, K.; Yu, T.; Huang, L.; Yang, B.; Zhang, X. Decentralized optimal multi-energy flow of large-scale integrated energy systems in a carbon trading market. Energy 2018, 149, 779-791. [CrossRef]

5. Wang, Y.; Yu, H.; Yong, M.; Huang, Y.; Zhang, F.; Wang, X. Optimal Scheduling of Integrated Energy Systems with Combined Heat and Power Generation, Photovoltaic and Energy Storage Considering Battery Lifetime Loss. Energies 2018, 11, 1676. [CrossRef]

6. Zhang, X.; Yu, T.; Zhang, Z.; Tang, J. Multi-Agent Bargaining Learning for Distributed Energy Hub Economic Dispatch. IEEE Access 2018, 6, 39564-39573. [CrossRef]

7. Borowy, B.S.; Salameh, Z.M. Optimum photovoltaic array size for a hybrid wind/PV system. IEEE Trans. Energy Convers. 1994, 9, 482-488. [CrossRef]

8. Wang, M.Q.; Gooi, H.B.; Chen, S.X.; Lu, S. A Mixed Integer Quadratic Programming for Dynamic Economic Dispatch with Valve Point Effect. IEEE Trans. Power Syst. 2014, 29, 2097-2106. [CrossRef]

9. Lin, W.-M.; Chen, S.-J. Bid-based dynamic economic dispatch with an efficient interior point algorithm. Int. J. Electr. Power Energy Syst. 2002, 24, 51-57. [CrossRef]

10. Ramanathan, R. Fast Economic Dispatch Based on the Penalty Factors from Newton's Method. IEEE Trans. Power App. Syst. 1985, PAS-104, 1624-1629. [CrossRef] 
11. Bakhshi, R.; Sadeh, J.; Mosaddegh, H.-R. Optimal economic designing of grid-connected photovoltaic systems with multiple inverters using linear and nonlinear module models based on Genetic Algorithm. Renew. Energy 2014, 72, 386-394. [CrossRef]

12. Deng, W.; Zhao, H.; Yang, X.; Xiong, J.; Sun, M.; Li, B. Study on an improved adaptive PSO algorithm for solving multi-objective gate assignment. Appl. Soft Comput. 2017, 59, 288-302. [CrossRef]

13. Dai, S.; Niu, D.; Han, Y. Forecasting of Power Grid Investment in China Based on Support Vector Machine Optimized by Differential Evolution Algorithm and Grey Wolf Optimization Algorithm. Appl. Sci. 2018, 8, 636. [CrossRef]

14. Yang, B.; Zhang, X.; Yu, T.; Shu, H.; Fang, Z. Grouped grey wolf optimizer for maximum power point tracking of doubly-fed induction generator based wind turbine. Energy Convers. Manag. 2017, 133, 427-443. [CrossRef]

15. Wang, L.; Zhou, Y.; Xu, J. Optimal Irregular Wind Farm Design for Continuous Placement of Wind Turbines with a Two-Dimensional Jensen-Gaussian Wake Model. Appl. Sci. 2018, 8, 2660. [CrossRef]

16. Carta, J.A.; Ramírez, P. Analysis of two-component mixture Weibull statistics for estimation of wind speed distributions. Renew. Energy 2007, 32, 518-531. [CrossRef]

17. Liu, Z.; Chen, C.; Yuan, J. Hybrid energy scheduling in a renewable micro grid. Appl. Sci. 2015, 5, 516-531. [CrossRef]

18. Hetzer, J.; Yu, D.C.; Bhattarai, K. An Economic Dispatch Model Incorporating Wind Power. IEEE Trans. Energy Convers. 2008, 23, 603-611. [CrossRef]

19. Salameh, Z.M.; Borowy, B.S.; Amin, A.R.A. Photovoltaic module-site matching based on the capacity factors. IEEE Trans. Energy Convers. 1995, 10, 326-332. [CrossRef]

20. Chen, S.X.; Gooi, H.B.; Wang, M.Q. Sizing of Energy Storage for Microgrids. IEEE Trans. Smart Grid 2012, 3, 142-151. [CrossRef]

21. Yang, B.; Yu, T.; Zhang, X.; Li, H.; Shu, H.; Sang, Y.; Jiang, L. Dynamic leader based collective intelligence for maximum power point tracking of PV systems affected by partial shading condition. Energy Convers. Manag. 2019, 179, 286-303. [CrossRef]

22. Bouchekara, H.R.E.H.; Chaib, A.E.; Abido, M.A. Optimal power flow using GA with a new multi-parent crossover considering: Prohibited zones, valve-point effect, multi-fuels and emission. Electr. Eng. 2018, 100, 151-165. [CrossRef]

23. Dinh, B.H.; Nguyen, T.T.; Quynh, N.V.; Van Dai, L. A Novel Method for Economic Dispatch of Combined Heat and Power Generation. Energies 2018, 11, 3113. [CrossRef]

24. Aghaei, J.; Alizadeh, M.-I. Multi-objective self-scheduling of CHP (combined heat and power)-based microgrids considering demand response programs and ESSs (energy storage systems). Energy 2013, 55, 1044-1054. [CrossRef]

25. Morshed, M.J.; Hmida, J.B.; Fekih, A. A probabilistic multi-objective approach for power flow optimization in hybrid wind-PV-PEV systems. Appl. Energy 2018, 211, 1136-1149. [CrossRef]

26. Liang, H.; Liu, Y.; Shen, Y.; Li, F.; Man, Y. A Hybrid Bat Algorithm for Economic Dispatch with Random Wind Power. IEEE Trans. Power Syst. 2018, 33, 5052-5061. [CrossRef]

27. Bhattacharya, A.; Chattopadhyay, P.K. Biogeography-Based Optimization for Different Economic Load Dispatch Problems. IEEE Trans. Power Syst. 2010, 25, 1064-1077. [CrossRef]

28. Freitas, C.A.O.D.; de Oliveira, R.C.L.; Silva, D.J.A.D.; Leite, J.C.; Junior, J.D.A.B. Solution to Economic-Emission Load Dispatch by Cultural Algorithm Combined with Local Search: Case Study. IEEE Access 2018, 6, 64023-64040. [CrossRef]

29. Yang, X.-S.; Sadat Hosseini, S.S.; Gandomi, A.H. Firefly Algorithm for solving non-convex economic dispatch problems with valve loading effect. Appl. Soft Comput. 2012, 12, 1180-1186. [CrossRef]

30. Li, C.; Li, S.; Liu, Y. A least squares support vector machine model optimized by moth-flame optimization algorithm for annual power load forecasting. Appl. Intell. 2016, 45, 1166-1178. [CrossRef]

31. Xu, T.; Meng, H.; Zhu, J.; Wei, W.; Zhao, H.; Yang, H.; Li, Z.; Ren, Y. Considering the Life-Cycle Cost of Distributed Energy-Storage Planning in Distribution Grids. Appl. Sci. 2018, 8, 2615. [CrossRef]

32. Nadeem, Z.; Javaid, N.; Malik, A.W.; Iqbal, S. Scheduling Appliances with GA, TLBO, FA, OSR and Their Hybrids Using Chance Constrained Optimization for Smart Homes. Energies 2018, 11, 888. [CrossRef]

33. Yang, Y.; Li, S.; Li, W.; Qu, M. Power load probability density forecasting using Gaussian process quantile regression. Appl. Energy 2018, 213, 499-509. [CrossRef] 
34. Suryanarayana, G.; Lago, J.; Geysen, D.; Aleksiejuk, P.; Johansson, C. Thermal load forecasting in district heating networks using deep learning and advanced feature selection methods. Energy 2018, 157, 141-149. [CrossRef]

35. Ahmad, T.; Chen, H. Short and medium-term forecasting of cooling and heating load demand in building environment with data-mining based approaches. Energy Build. 2018, 166, 460-476. [CrossRef]

36. Mohammadi-Ivatloo, B.; Moradi-Dalvand, M.; Rabiee, A. Combined heat and power economic dispatch problem solution using particle swarm optimization with time varying acceleration coefficients. Electr. Power Syst. Res. 2013, 95, 9-18. [CrossRef]

37. Beigvand, S.D.; Abdi, H.; La Scala, M. Combined heat and power economic dispatch problem using gravitational search algorithm. Electr. Power Syst. Res. 2016, 133, 160-172. [CrossRef]

38. Piperagkas, G.S.; Anastasiadis, A.G.; Hatziargyriou, N.D. Stochastic PSO-based heat and power dispatch under environmental constraints incorporating CHP and wind power units. Electr. Power Syst. Res. 2011, 81, 209-218. [CrossRef]

39. Zhao, J.; Wen, F.; Dong, Z.Y.; Xue, Y.; Wong, K.P. Optimal Dispatch of Electric Vehicles and Wind Power Using Enhanced Particle Swarm Optimization. IEEE Trans. Ind. Inform. 2012, 8, 889-899. [CrossRef]

40. Karaki, S.H.; Chedid, R.B.; Ramadan, R. Probabilistic performance assessment of autonomous solar-wind energy conversion systems. IEEE Trans. Energy Convers. 1999, 14, 766-772. [CrossRef]

(C) 2019 by the authors. Licensee MDPI, Basel, Switzerland. This article is an open access article distributed under the terms and conditions of the Creative Commons Attribution (CC BY) license (http:/ / creativecommons.org/licenses/by/4.0/). 